\title{
Munc13-4 mediates human neutrophil elastase-induced airway mucin5AC hypersecretion by interacting with syntaxin2
}

\author{
RUI XU ${ }^{1}$, JIA ZHOU ${ }^{2}$, XIANG-DONG ZHOU ${ }^{3}$, QI LI ${ }^{3}$, JULIY M. PERELMAN ${ }^{4}$ and VICTOR P. KOLOSOV ${ }^{4}$ \\ ${ }^{1}$ Department of Respiratory Medicine, The Second Affiliated Hospital of Chongqing Medical University, Chongqing 400010; \\ ${ }^{2}$ Department of Respiratory Medicine, The First Affiliated Hospital of Chongqing Medical University, Chongqing 400016; \\ ${ }^{3}$ Department of Respiratory Medicine, The First Affiliated Hospital of Hainan Medical University, Haikou, \\ Hainan 570102, P.R. China; ${ }^{4}$ Far Eastern Scientific Center of Physiology and Pathology of \\ Respiration, Russian Academy of Medical Sciences, Blagoveshchensk 675000, Russia
}

Received August 8, 2017; Accepted March 27, 2018

DOI: $10.3892 / \mathrm{mmr} .2018 .9015$

\begin{abstract}
The overexpression and hypersecretion of mucus is a hallmark of chronic pulmonary inflammatory disease. Mucin5AC (MUC5AC) is a major component of airway gel-forming mucin. Members of the Unc13 (Munc13) protein family act as important activators of granule exocytosis from various types of mammalian cells. The present study aimed to determine the role of Munc13 family proteins in MUC5AC secretion via an in vitro study with BEAS-2B and Calu-3 cell lines. Reverse transcription-quantitative polymerase chain reaction and western blotting indicated that stimulation of the cells with $100 \mathrm{nM}$ human neutrophil elastase (hNE) for $1 \mathrm{~h}$ did not affect the expression of either unc13 homolog B (Munc13-2) or unc13 homolog D (Munc13-4), but immunofluorescence analysis demonstrated that $\mathrm{hNE}$ treatment was associated with the recruitment of Munc13-4 to the plasma membrane. Co-immunoprecipitation analysis indicated increased binding between Munc13-4 and syntaxin2 followingh NE stimulation; however, Munc13-2 formed a stable interaction with syntaxin2 with or without hNE stimulation. Subsequently, Munc13-2 and Munc13-4 expression levels were downregulated in BEAS-2B and Calu-3 cells using small interfering RNA (siRNA). ELISAs and immunofluorescence analysis were performed to assess MUC5AC secretion and intracellular retention, respectively. Munc13-2 siRNA transfection did not alter the expression levels of intracellular or secreted MUC5AC following hNE stimulation in either cell line; however, it increased the baseline intracellular levels of MUC5AC and decreased the amount of secreted MUC5AC. Conversely, Munc13-4 siRNA transfection increased the intracellular levels of MUC5AC
\end{abstract}

Correspondence to: Professor Xiang-Dong Zhou, Department of Respiratory Medicine, The First Affiliated Hospital of Hainan Medical University, 31 Longhua Road, Haikou, Hainan 570102, P.R. China

E-mail: zxd999@263.net

Key words: mucin 5AC, Munc13, human neutrophil elastase and decreased the amount of secreted MUC5AC following hNE stimulation, but did not affect their baseline quantities. The results of the present study indicate that Munc13-2 may be an essential regulator of basal MUC5AC exocytosis, while Munc13-4 appears to be a Munc13 protein subtype that may to be sensitive to hNE stimulation during airway MUC5AC hypersecretion.

\section{Introduction}

Goblet cells, which secret mucins, are expressed throughout mammalian airway tracts, where they function in the hydration, lubrication and clearance of particles and pathogens from the underlying airway epithelium (1). Goblet cells in the lung are the primary secretory cells in the superficial epithelium. Under normal conditions, the secretion of airway mucus maintains airway hydration and traps particles and pathogenic microorganisms (2); however, mucus hypersecretion is a hallmark of various pulmonary inflammatory diseases, including chronic obstructive pulmonary disease (COPD), asthma and cystic fibrosis (2). The major gel-forming mucin in the human airway, mucin5AC (MUC5AC), is primarily synthesized by goblet cells. Excessive secretion of gel-forming mucins, MUC5AC in particular, has been observed in mortalities that were a result of a severe asthma attack or acute exacerbation of COPD (3).

The process of MUC5AC secretion into the airway lumen is strictly controlled and occurs via calcium-dependent exocytosis of MUC5AC-containing granules from epithelial goblet or mucous cells. Dysregulation of mucin secretion leads to adverse alterations in the mucociliary clearance activity and the subsequent development of obstructive pulmonary disease. Mucin secretion is a highly regulated process that requires certain proteins involved in the exocytosis of mucin granules, such as exocyst family members and ezrin $(4,5)$, to be recruited. The fusion of mucin granules and target cellular membranes depends on the formation of soluble $\mathrm{N}$-ethylmaleimide-sensitive factor attachment protein receptor (SNARE) compounds (6). The core SNAREs, namely vesicle-associated membrane protein 8 (VAMP8), which is a vesicular SNARE protein present on secretory 
vesicles (v-SNAREs), and synaptosome-associated protein 23 (SNAP23), which is a SNARE protein present on target membranes (t-SNAREs), in airway goblet cells are responsible for the exocytosis of MUC5AC granules $(2,7)$. In calcium-dependent exocytosis, granule activation is a key rate-limiting step; when MUC5AC granules are activated, they acquire the ability to fuse with target membranes, a process that depends on the presence of calcium, diacylglycerol (DAG), syntaxin, synaptotagmin and other factors (8).

Members of the Munc13 protein family act as important activators of granule secretion in a wide variety of mammalian cells. To date, four subtypes of Munc13, termed unc13 homologs A to D (Munc13-1 to Munc13-4), have been isolated from mammalian cells. All of the Munc13 subtypes contain numerous $\mathrm{C} 2$ domains, some of which bind calcium and phospholipids, while others appear to be specialized for protein-protein interactions $(9,10)$. Additionally, a $\mathrm{C} 1$ domain that is able to bind DAG is present in all Munc13 subtypes, excluding Munc13-4; this site is also the major pharmacological target of phorbol esters, which stimulate synaptic transmission (11). Munc13 proteins also contain a MUN domain, which is an $\alpha$-helical region that allows the direct or indirect interaction of Munc13 proteins with syntaxin. This interaction is essential in the ability of the Munc13 family members to regulate granule exocytosis (11). In neurons, Munc13-1 activation by DAG leads to the translocation of Munc13-1 to the plasma membrane, where it subsequently forms a tripartite complex with Rab3a on tethered vesicles and Rab3a-interacting molecule on the plasma membrane; however, only Munc13-2 and Munc13-4 are expressed in the human airway (12). Analysis in mice has demonstrated that Munc13-2 is a mucin granule activator that aids the regulation of baseline secretion (13). Additionally, upon stimulation with extracellular ATP, intracellular mucin release was maintained in Munc13-2-mutant mice, indicating that other mechanisms may support agonist-regulated mucin secretion (13). It has been revealed that Munc13 may interact with distinct SNARE proteins, such as those of the syntaxin family (14); however, whether Munc13-4, a recently discovered Munc13 family member, participates in agonist-stimulated MUC5AC granule secretion, and the associated underlying mechanisms, requires further investigation (15).

\section{Materials and methods}

Cells, reagents and antibodies. SV40-immortalized human bronchial epithelial cells (BEAS-2B) and a human lung adenocarcinoma cell line (Calu-3) were purchased from the American Type Culture Collection (Manassas, VA, USA). Fetal bovine serum (FBS) was purchased from Invitrogen (Thermo Fisher Scientific, Inc., Waltham, MA, USA). Human neutrophil elastase (hNE) and Dulbecco's modified Eagle's medium (DMEM) were purchased from Sigma-Aldrich (Merck KGaA, Darmstadt, Germany). Primary antibodies, including rabbit anti-human syntaxin 2 (ab12369), rabbit anti-human Munc13-2 (ab97924), rabbit anti-human Munc13-4 (ab109113) and mouse anti-human MUC5AC antibodies (ab218466) were purchased from Abcam (Cambridge, MA, USA). An internal reference $\beta$-actin antibody (TA890010) and secondary antibodies, including horseradish peroxidase (HRP)-conjugated goat anti-rabbit IgG (TA130023), fluorescein isothiocyanate (FITC)-conjugated goat anti-rabbit IgG (TA130022), and HRP-conjugated goat anti-mouse IgG (TA130005) were purchased from OriGene Technologies, Inc. (Beijing, China). Tetramethylrhodamine (TRITC)-conjugated goat anti-mouse IgG (BA1089-0.5) was purchased from Wuhan Boster Biological Technology, Ltd., Wuhan, China.

Cell culture. The BEAS-2B and Calu-3 cell lines were cultured in DMEM with $10 \%$ FBS, penicillin $(100 \mathrm{IU} / \mathrm{ml})$ and streptomycin $(100 \mathrm{IU} / \mathrm{ml})$ at $37^{\circ} \mathrm{C}$ in a $5 \% \mathrm{CO}_{2}$ incubator and were passaged when cells were $80-90 \%$ confluent. Cells at the $3 \mathrm{rd}$ passage were used for subsequent analysis.

MTT [3-(4,5-dimethylthiazol-2-ul)-2,5-diphenyltetrazolium bromide] assay. Cells treated with $100 \mathrm{nM} \mathrm{hNE}$ according to the experimental requirements were plated at 96-well plates at a density of 5,000 cells/well. The MTT reagent, with a finial concentration of $5 \mathrm{mg} / \mathrm{ml}$, (E606334-0500; Sangon Biotech Co., Ltd., Shanghai, China) was added to each well at the indicated time points $(0,20,40,60$ and $80 \mathrm{~min})$ and incubated for $4 \mathrm{~h}$ at $37^{\circ} \mathrm{C}$. The optical density (OD) was read at $570 \mathrm{~nm}$ on a microplate spectrophotometer. Each group had 5 repeat wells to ensure the accuracy of the experiment.

Small interfering RNA (siRNA) preparation and transfection. A human Munc13-2-specific siRNA plasmid, a human Munc13-4-specific siRNA plasmid and control siRNA plasmids, were transfected into cells. The vector pGC-silencer-U6/Neo/ GFP was purchased from Santa Cruz Biotechnology, Inc. (Dallas, TX, USA). siRNA sequences used were Munc13-2 5'-GGCCUGCUUGAACUCUACAUA UGAA-3', and Munc13-4 5'-CCAGCCCAGCUACACUGU ACACUUU-3'. Munc13-2 and Munc13-4 control siRNAs were scrambled siRNAs containing the similar GU content as Munc13-2 siRNA and Munc13-4 siRNA, respectively. Prior to transfection, cells in the exponential growth phase were plated in 6-well cell culture plates and incubated at $37^{\circ} \mathrm{C}$ for $12 \mathrm{~h}$. Each well had a basal area of $9.6 \mathrm{~cm}^{2}$ and contained $\sim 4 \times 10^{6}$ cells. Following washing with PBS three times to avoid any interference caused by antibiotics or serum, the cells were transfected using FuGENE ${ }^{\circledR}$ HD reagent (E2311; Promega Corporation, Madison, WI, USA) with Munc13-2-specific siRNA, Munc13-4-specific siRNA or control siRNA (20 $\mu \mathrm{g}$ DNA: $60 \mu \mathrm{l}$ transfection reagent) at $22^{\circ} \mathrm{C}$ for $15 \mathrm{~min}$ according to the manufacturer's protocol. Following transfection, cells were washed with PBS three times. Cells were incubated in the full culture medium for $24 \mathrm{~h}$ at $37^{\circ} \mathrm{C}$, prior to western blotting, RT-qPCR, ELISA and immunofluorescence).

Co-immunoprecipitation (CoIP). CoIP was performed using a Co-Immunoprecipitation kit (26149; Pierce; Thermo Fisher Scientific, Inc.) according to the manufacturer's protocol. Cells were washed three times with PBS and lysed on ice for $30 \mathrm{~min}$ using IP lysis buffer (Beyotime Institute of Biotechnology, Shanghai, China) with protease inhibitors (Thermo Fisher Scientific, Inc.). To remove nuclei and intact cells, the lysates were centrifuged at $20,000 \mathrm{xg}$ for $15 \mathrm{~min}$ at $4^{\circ} \mathrm{C}$. Protein A agarose was washed, diluted 50\% with PBS and added to the protein at a 1:10 $(\mathrm{v} / \mathrm{v})$ ratio. The mixture was agitated on a 
Table I. Reverse transcription-quantitative polymerase chain reaction primers.

\begin{tabular}{lll}
\hline Target gene & \multicolumn{1}{c}{ Forward primer $\left(5^{\prime}-3^{\prime}\right)$} & \multicolumn{1}{c}{ Reverse primer $\left(5^{\prime}-3^{\prime}\right)$} \\
\hline Munc13-2 & CTTCCTACTCCTGTAAGCAGGG & TGTTGACTGGCGCATTGTGG \\
Munc13-4 & AGGGAAGCCCTTCATCCTGT & TCTGTAGACAGCCAAACTCC \\
MUC5AC & ACTTTGATGCTGAGCGGGATG & CGAAGGCAATATCCTGTCTCTGTG \\
GAPDH & AGAAGGCTGGGGCTCATTTG & AGGGGCCATCCACAGTCTTC
\end{tabular}

Munc13-2, unc-13 homolog B; Munc13-4, unc-13 homolog D; MUC5AC, mucin 5AC.

shaking table for $30 \mathrm{~min}$ at $4^{\circ} \mathrm{C}$ and subsequently centrifuged at $20,000 \mathrm{x}$ g for $15 \mathrm{~min}$ at $4^{\circ} \mathrm{C}$ for supernatant collection. The supernatants were standardized at $5 \mu \mathrm{g} / \mu \mathrm{l}$ for equal protein loading via a Bicinchoninic Acid Protein assay kit (Beyotime Institute of Biotechnology), according to the manufacturer's protocol. Subsequently, $5 \mu \mathrm{g}$ rabbit anti-human syntaxin 2 (1:200 dilution) was added to an Eppendorf tube containing $500 \mu \mathrm{l}$ cell lysate and the mixture was agitated on a shaking table at $4^{\circ} \mathrm{C}$ overnight. The antigen-antibody complexes were captured by adding $100 \mu \mathrm{l}$ Protein A agarose and incubating at room temperature for $90 \mathrm{~min}$. Following centrifugation at $20,000 \times \mathrm{g} 4^{\circ} \mathrm{C}$ for $1 \mathrm{~min}$, the Protein A agarose bound to the antigen-antibody complexes was washed three times with ice-cold PBS. The precipitates were mixed with $5 \mathrm{X}$ western blot loading buffer and boiled for $5 \mathrm{~min}$. Following centrifugation at $20,000 \times \mathrm{g} 4^{\circ} \mathrm{C}$ for $15 \mathrm{~min}$, the supernatants were separated via SDS-PAGE as described in the following 'western blotting' section.

Western blotting. The expression levels of the proteins of interest in the cellular lysate supernatants were detected via western blotting. Generally, cells were washed with PBS three times and lysed on ice for 20 min using an IPlysis buffer (P0013; Beyotime Institute of Biotechnology). To remove nuclei and intact cells, the lysates were centrifuged at $20,000 \mathrm{x}$ g for $15 \mathrm{~min}$ at $4^{\circ} \mathrm{C}$. Supernatants were standardized for equal protein concentration $(5 \mu \mathrm{g} / \mu \mathrm{l})$ using a Bicinchoninic Acid Protein Assay kit (Beyotime Institute of Biotechnology). Following separation by SDS-PAGE (6\% SDS separation gel for Munc13-2 and Munc13-4, 10\% SDS separation gel for syntaxin 2 and $\beta$-actin), proteins were transferred onto polyvinylidene difluoride (PVDF) membranes, which were blocked with 5\% skimmed milk for $1 \mathrm{~h}$ at a room temperature $\left(22^{\circ} \mathrm{C}\right)$ and incubated with anti-Munc13-2 antibody (1:1,000 dilution), anti-Munc13-4 antibody (1:5,000 dilution), anti-human syntaxin 2 antibody (1:1,000 dilution) and anti- $\beta$-actin antibody (1:200 dilution) at $4^{\circ} \mathrm{C}$ overnight. Following three washes with PBS with Tween-20 $(0.05 \%)$ for 15 min each, the PVDF membranes were incubated with HRP-conjugated goat anti-rabbit $\mathrm{IgG}$ at a 1:2,000 dilution for $2 \mathrm{~h}$ at room temperature $\left(22^{\circ} \mathrm{C}\right)$. The blots were visualized using enhanced chemiluminescence according to the protocol of the New-SUPER ECL kit (KGP1127; Nanjing KeyGen Biotech Co., Ltd., Nanjing, China). The intensity of each band was measured using a Fluor-S Multi Imager and Quantity One version 4.6.2 software (Bio-Rad Laboratories, Inc., Hercules, CA, USA). The expression levels of the proteins of interest were normalized to that of $\beta$-actin.
Reverse transcription-quantitative polymerase chain reaction (RT-qPCR) analysis. Total RNA was extracted from cells using TRIzol (Thermo Fisher Scientific, Inc.). The extraction was confirmed by RNA electrophoresis on a $1.5 \%$ agarose gel and an absorbance $\left(\mathrm{A}_{260 / 280}\right)$ value of 1.8-2.0 was deemed acceptable. RT was performed using an iScript cDNA Synthesis kit (1708891; Bio-Rad Laboratories, Inc.) according to the manufacturer's protocol. The reaction conditions for RT were $5 \mathrm{~min}$ at $25^{\circ} \mathrm{C}, 30 \mathrm{~min}$ at $42^{\circ} \mathrm{C}, 5 \mathrm{~min}$ at $85^{\circ} \mathrm{C}$, and hold at $4^{\circ} \mathrm{C}$. Synthesized cDNA $(0.1 \mu \mathrm{g} / \mu \mathrm{l})$ was prepared for qPCR, which was performed using iQ SYBR Green Supermix (Bio-Rad Laboratories, Inc.) with qPCR primers in an iCycler thermal cycler (Bio-Rad Laboratories, Inc.). Generally, qPCR conditions were pre-denaturation at $95^{\circ} \mathrm{C}$ for $3 \mathrm{~min}$ followed by 35 cycles of denaturation at $95^{\circ} \mathrm{C}$ for $10 \mathrm{sec}$, annealing and elongation at $55^{\circ} \mathrm{C}$ for $40 \mathrm{sec}$. To quantify the expression levels of MUC5AC, Munc13-2 and Munc13-4 mRNA, GAPDH mRNA was used as an internal control. All of the primers used for the qPCR experiments are listed in Table I. The qPCR curves were analyzed using CFX Manager ${ }^{\mathrm{TM}}$ software version 3.1 (Bio-Rad Laboratories, Inc.) to obtain quantification cycle $(\mathrm{Cq})$ values for each sample (16). mRNA expression was calculated based on the generated standard curve.

Detection of MUC5AC concentrations in cell supernatants by ELISA. Secreted MUC5AC in cell culture supernatants was assessed via ELISA assays. Then, $24 \mathrm{~h}$ following transfection, the culture supernatants $(50 \mu \mathrm{l} /$ well) were added to a 96 -well plate and incubated at $40^{\circ} \mathrm{C}$ until dry. Following the washing of the wells and blocking with $2 \%$ FBS (Gibco; Thermo Fisher Scientific, Inc.) for $1 \mathrm{~h}$ at room temperature, a mouse monoclonal antibody against MUC5AC (1:200 dilution) was incubated in the wells for $1 \mathrm{~h}$ at room temperature. The plates were washed three times with PBS and incubated with $100 \mu \mathrm{l} /$ well of HRP-conjugated goat anti-mouse IgG at 1:5,000 dilution. After $1 \mathrm{~h}$ incubation at room temperature, the plates were washed three times with PBS. 3,3',5,5'-tetramethylbenzidineperoxidase solution (P0209; Beyotime Institute of Biotechnology) was used to produce a color reaction, which was terminated upon the addition of $\mathrm{H}_{2} \mathrm{SO}_{4}$. The absorbance was read at $450 \mathrm{~nm}$ and the results were expressed as the ratio of MUC5AC to the untransfected cells without hNE treatment (the CTL NT group).

Immunofluorescence staining and laser confocal microscopy. Direct visual observation of Munc13 protein family members and intracellular MUC5AC protein was performed by 
immunofluorescence staining and laser confocal microscopy. Cells were plated at a density of $2 \times 10^{5} / \mathrm{ml}$ on a glass coverslip in each well of 24-well plates. Following three washes with PBS, the cells were fixed with a formaldehyde solution freshly prepared from $4 \%$ paraformaldehyde (dissolved in PBS) for $10 \mathrm{~min}$ at room temperature and were washed again with PBS. The fixed cells were permeabilized with $0.1 \%$ Triton X-100 in PBS for $3 \mathrm{~min}$ at room temperature and washed three times with PBS. The cells were subsequently blocked in 5\% goat serum (AR0009; Wuhan Boster Biological Technology, Ltd.) for $60 \mathrm{~min}$ and incubated with mouse anti-MUC5AC antibody (1:500 dilution), rabbit anti-Munc13-2 antibody (1:100 dilution) or rabbit anti-Munc13-4 antibody (1:100 dilution) at $4^{\circ} \mathrm{C}$ overnight. Following three washes with PBS, the slides were incubated with TRITC-linked goat anti-mouse IgG (1:200 dilution) or FITC-conjugated goat anti-rabbit IgG (1:200 dilution) for $60 \mathrm{~min}$ at room temperature. The cells were then washed 3 times with PBS and incubated with 100 ng/ml 4',6-Diamidino-2-Phenylindole, Dihydrochloride (DAPI; C1002; Beyotime Institute of Biotechnology) for $3 \mathrm{~min}$ at room temperature. Following washing 5 times with PBS, the cells were mounted in 50\% glycerol and visualized using a confocal laser microscope (TCSSP2; Leica Microsystems $\mathrm{GmbH}$, Wetzlar, Germany). Representative images were captured and processed with Adobe Photoshop version 7.0 (Adobe Systems, Inc., San Jose, CA, USA). A total of 20 cells on each slide were evaluated for each condition. The fluorescence intensity (original magnification, $\mathrm{x} 400$ ) and line scan (magnification, x800) analysis (17) were recorded and calculated using Leica Microsystem (LeicaTCS SP2).

Statistical analysis. Data are presented as the mean \pm standard deviation of six independent experiments. All data were analyzed using the SPSS 17.0 statistical package (SPSS, Inc., Chicago, IL, USA). One-way analysis of variance followed by a Student-Newman-Keuls test was performed to compare differences between groups. $\mathrm{P}<0.05$ was considered to indicate a statistically significant difference.

\section{Results}

Cell viability and the effect of hNE stimulation on Munc13 synthesis. Cell viability was assessed using a conventional MTT reduction assay. The results revealed no significant decreases in the viability of BEAS-2B or Calu-3 cells following exposure to $100 \mathrm{nM} \mathrm{hNE}$ for up to $1 \mathrm{~h}$ (Fig. 1). Thus, $1 \mathrm{~h}$ was selected as the appropriate exposure time for subsequent experiments.

Subsequently, the present study investigated whether hNE influenced the synthesis of Munc13-2 or Munc13-4 in human airway epithelial cell lines. The results of RT-qPCR and western blotting demonstrated stable and unaltered mRNA and protein expression of Munc13-2 and Munc13-4 prior to and following stimulation with hNE in both cell lines (Fig. 2). To examine the cellular distribution of Munc13-2 and Munc13-4 in cells induced to hypersecrete MUC5AC by hNE, the present study conducted cell immunofluorescence staining and laser confocal microscopy of BEAS-2B and Calu-3 cells (Fig. 3A). Upon hNE application, the plasma membrane fluorescence intensity/cellular mean fluorescence intensity ratios

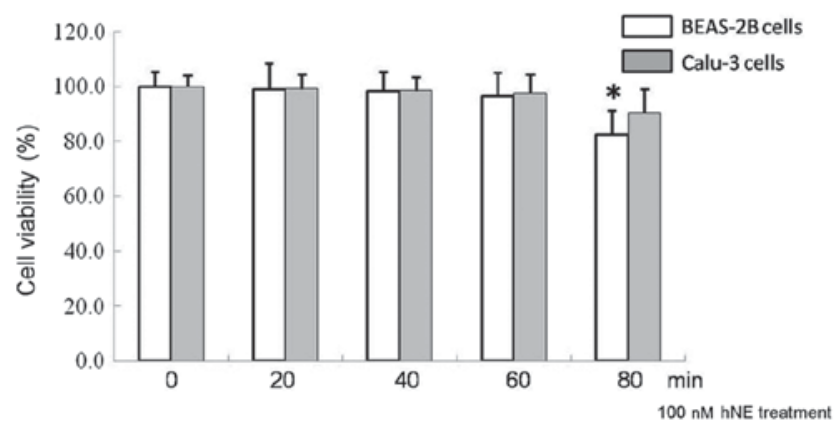

Figure 1. An MTT assay was performed to investigate cell viability. In the test, $100 \mathrm{nM}$ hNE was added to each experimental well in a 96-well plate. The results were recorded as the percentage of living cells compared with the respective control groups. ${ }^{*} \mathrm{P}<0.05$ vs. respective 0 min control group. $\mathrm{hNE}$, human neutrophil elastase.

of Munc13-4 were significantly increased compared with in the respective control groups, indicating the recruitment of Munc13-4 to the cellular membrane (Fig. 3). Prior to hNE stimulation, Munc13-4 exhibited cytoplasmic distribution (Fig. 3). Conversely, no marked alterations in the cellular distribution of Munc13-2 were observed upon hNE application (Fig. 3).

hNE increases the binding of Munc13-4 to syntaxin2 during MUC5AC hypersecretion. Previous in vitro studies using membrane-integrated SNARE proteins to reveal the SNARE-binding properties of the Munc13 protein family members have reported that an interaction exists between the $\mathrm{N}$-terminus of Munc13 and syntaxin $(14,18,19)$. Syntaxin is a crucial SNARE component whose C-terminus binds to the plasma membrane. Syntaxin 1 , syntaxin 2 and syntaxin 3 are all present in human airway epithelial cells $(20,21)$ and syntaxin 2 serves a crucial role in regulating the exocytosis of mucin granules (22). In mammalian endocrine cells, Munc13 was reported to competitively bind to syntaxin and release Munc18 during the exocytosis of secretory granules (SGs) $(14,23)$. In the present study, CoIP assays demonstrated that Munc13-2 binds to syntaxin2 with or without hNE pretreatment in BEAS-2B and Calu-3 cells (Fig. 4). Conversely, Munc13-4 demonstrated limited levels of binding to syntaxin 2 in the absence of hNE pretreatment, with enhanced binding observed following pretreatment with hNE (Fig. 4).

siRNA-mediated downregulation of Muncl3-2 or Munc13-4 does not affect MUC5AC mRNA expression. siRNA was used to inhibit Munc13-2 or Munc13-4 expression, and the downregulation of expression was verified by western blotting (Fig. 5). MUC5AC mRNA expression levels were investigated in untransfected cells and Munc13-knockdown cells using RT-qPCR analysis. The untransfected cells served as a negative control. The MUC5AC mRNA expression levels were normalized to that of GAPDH and the results were expressed as fold changes compared with the untransfected cells. The findings of the present study revealed no significant differences in MUC5AC mRNA expression among the Munc13-2 knockdown cells, Munc13-4 knockdown cells, control siRNA-transfected cells and untransfected cells (Fig. 6). 
A
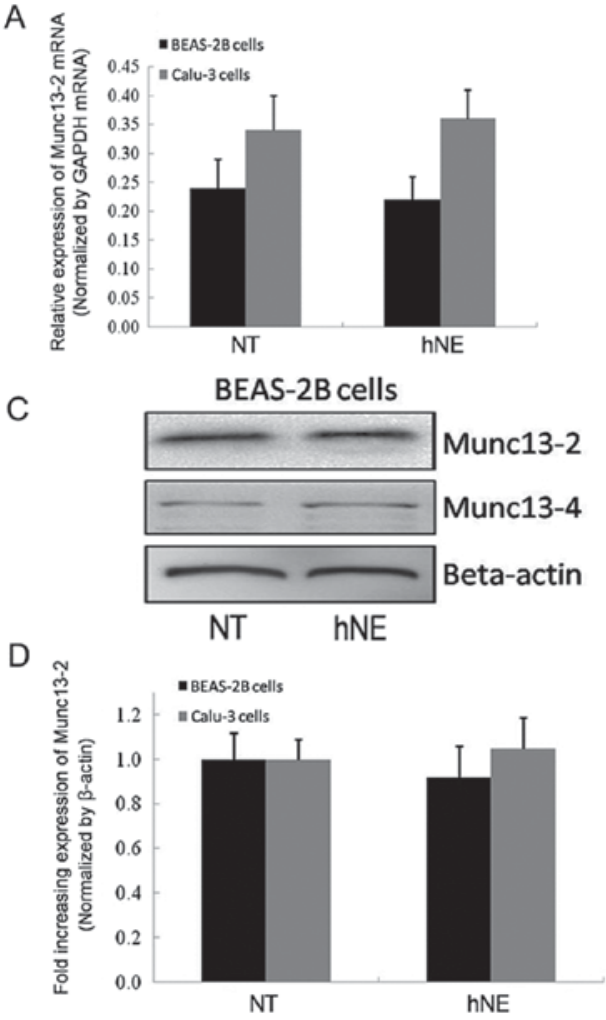

B

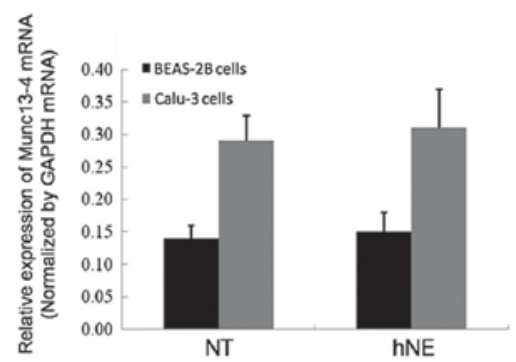

Calu-3 cells

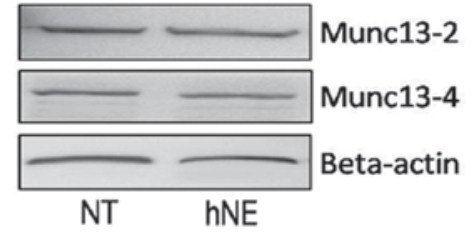

$\mathrm{E}$

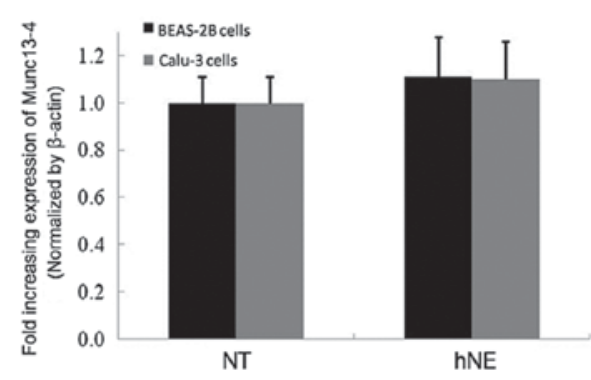

Figure 2. Effects of $100 \mathrm{nM}$ hNE on the cellular synthesis of Munc13-2 and Munc13-4. Experiments were performed in6-well plates. After 1 h of stimulation, total mRNA was extracted and analyzed by reverse transcription-quantitative polymerase chain reaction. The relative amounts of (A) Munc13-2 and (B) Munc13-4 mRNA were recorded and normalized to the GAPDH mRNA expression levels. The results were expressed as Munc13 mRNA/GAPDH mRNA levels. (C) Cellular lysates containing total protein were normalized and separated via SDS-PAGE gels for western blot analysis. Representative bands are presented for each protein. The relative amounts of (D) Munc13-2 protein and (E) Munc13-4 protein were recorded and normalized to the amount of $\beta$-actin. A total of six independent blots were analyzed and the results were presented as fold increases in Munc13/ $\beta$-actin compared with the NT controls. hNE, human neutrophil elastase; Munc13-2, unc-13 homolog B; Munc13-4, unc-13 homolog D; NT, no hNE treatment.

Munc13-4 participates in the MUC5AC hypersecretion induced by $h N E$. As Munc13-4 is recruited to the plasma membrane and interacts with syntaxin 2 , which has been demonstrated to serve a crucial role in MUC5AC granule exocytosis (22), the present study employed siRNA to downregulate Munc13-2 or Munc13-4 in the two cell lines to determine whether either of these proteins are necessary for the hypersecretion of MUC5AC.

Compared with cells that did not receive hNE stimulation, the quantity of retained intracellular MUC5AC protein was marginally increased in the control untransfected cells and control siRNA-transfected cells (CTL siRNA1 and CTL siRNA2) following hNE stimulation (Fig. 7). In particular, the levels of retained intracellular MUC5AC increased by $\sim 1.54$ and 1.29-fold in Munc13-2 siRNA-transfected BEAS-2B and Calu-3 cells without hNE treatment, respectively, compared with in wild-type cells without hNE treatment (Fig. 7). However, following stimulation with hNE, there was no significant difference in intracellular red fluorescence intensity between Munc13-2 siRNA-transfected and wild-type cells (Fig. 7). Furthermore, no significant differences in intracellular fluorescence intensity were detected between Munc13-4-knockdown cells and untransfected cells without hNE stimulation; however, a $\sim 3$-fold increase in intracellular fluorescence intensity was detected in Munc13-4-knockdown BEAS-2B and Calu-3 cells compared with in wild-type cells following stimulation with hNE (Fig. 7).
ELISAs were used to detect MUC5AC in cell supernatants and the results indicated that Munc13-4 may serve a major role in hNE-induced MUC5AC exocytosis, concordant with the laser confocal microscopy analysis results of retained intracellular MUC5AC. The concentrations of MUC5AC protein in cell culture supernatants were presented as fold changes compared with in untransfected cells without hNE stimulation (Fig. 8). Generally, neither the CTL siRNA for Munc13-2 or Munc13-4 (CTL siRNA1 and 2, respectively) significantly affected the MUC5AC protein concentration in the cell culture supernatants prior to or following hNE stimulation (Fig. 8). The levels of secreted MUC5AC protein in the culture supernatants of Munc13-2-knockdown BEAS-2B cells were decreased by $\sim 0.30$-fold compared with the untransfected BEAS-2B cells without hNE treatment. However, the levels between these two groups following hNE treatment became no longer significantly different (Fig. 8A). Similar results were observed for Calu-3 cells (Fig. 8B). These findings are consistent with analysis conducted within mouse models (13) and indicate that Munc13-2 may be a key regulator of baseline MUC5AC secretion. The levels of secreted MUC5AC protein in the culture supernatants of Munc13-4-knockdown BEAS-2B cells were not significantly different from those in the supernatants of untransfected BEAS-2B cells without hNE treatment, whereas Munc13-4-knockdown BEAS-2B cells subjected to hNE pretreatment exhibited only $60 \%$ of the 


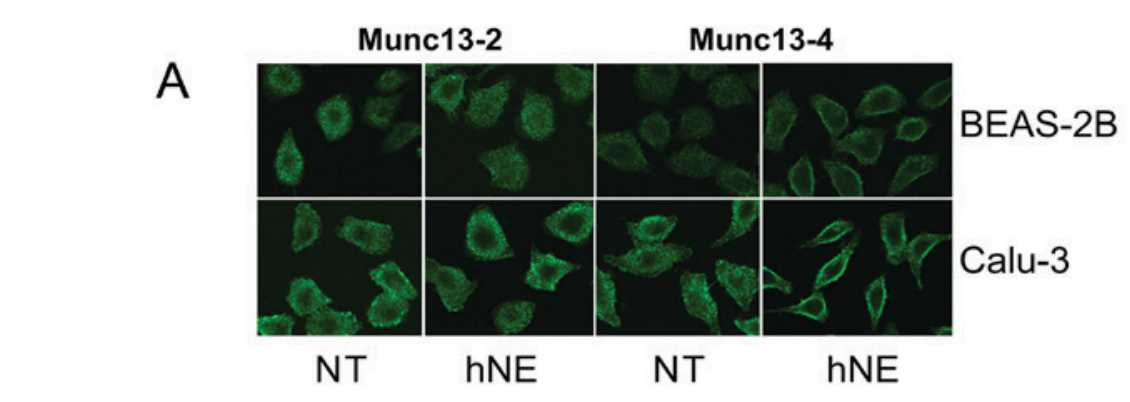

B

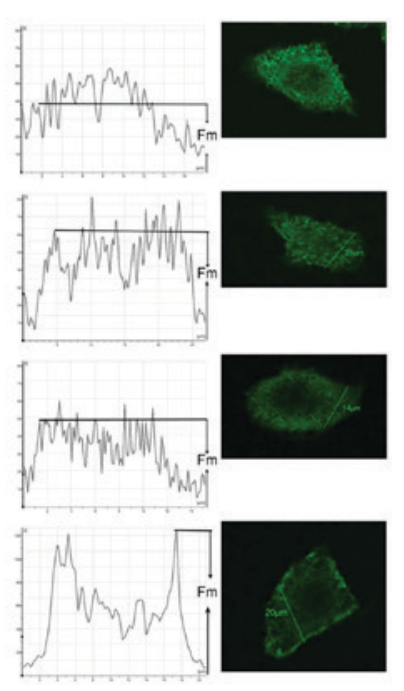

BEAS-2B

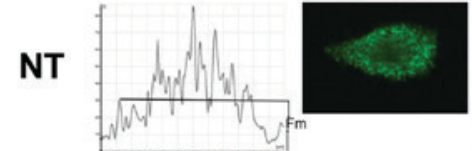

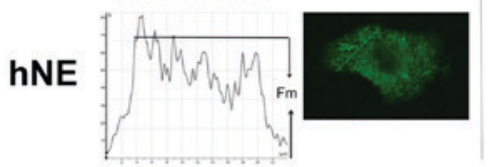
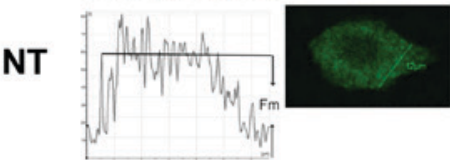

hNE

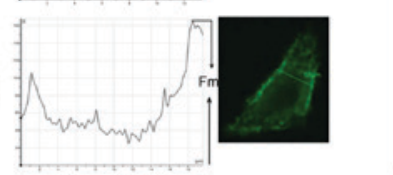

Calu-3
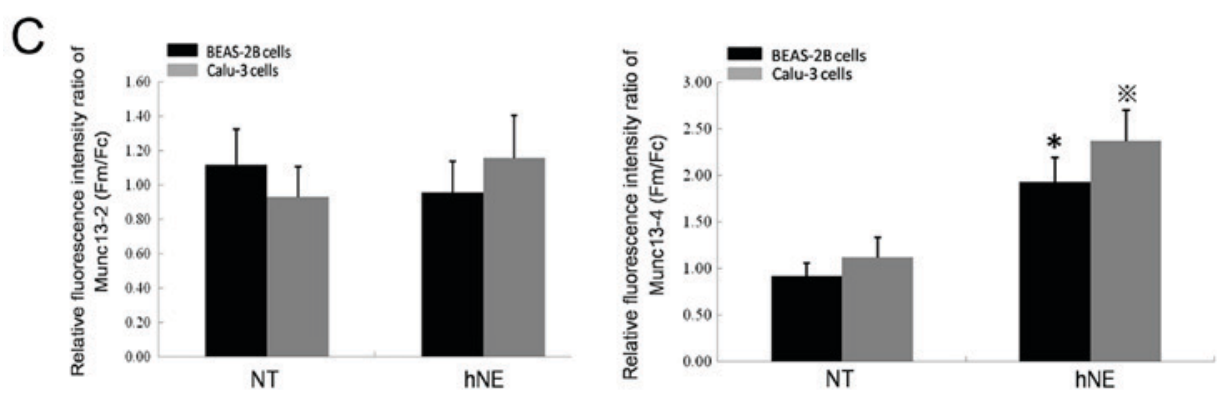

Figure 3. Intracellular distributions of Munc13-2 and Munc13-4 following treatment with hNE. BEAS-2B cells and Calu-3 cells were treated for $1 \mathrm{~h}$ with a hNE solution at a final concentration of $100 \mathrm{nM}$. Cells treated with the same volume of PBS served as the NT group. Munc13-2 and Munc13-4 were visualized using cell immunofluorescence staining and laser confocal microscopy. (A) Images were recorded using a laser confocal microscope at an original magnification of $\mathrm{x} 800$ in six independent experiments. (B) Line scans of BEAS-2B cells and Calu-3 cells. Original magnification x800. (C) Total intracellular green fluorescence intensity was calculated and recorded as the mean intracellular fluorescence intensity. The ratios of Fm/Fc were recorded A total of 20 cells on each slide were evaluated for each condition. " $\mathrm{P}<0.05$ vs. NT BEAS-2B cells; ${ }^{*} \mathrm{P}<0.05$ vs. NT Calu-3 cells. Munc13-2, unc-13 homolog B; Munc13-4, unc-13 homolog D; hNE, human neutrophil elastase; NT, no hNE treatment; Fm, membrane fluorescence intensity; FC, mean intracellular fluorescence intensity.

secreted MUC5AC protein levels of untransfected BEAS-2B cells (Fig. 8A). Similar data were obtained for the Calu-3 cell line (Fig. 8B). These results indicate that Munc13-4 may serve a crucial role in the excess secretion of MUC5AC induced by hNE stimulation but may not be involved in maintaining baseline secretion levels.

\section{Discussion}

In respiratory diseases, various stimuli, including infectious agents, irritants and allergy-associated stimuli, leads to increases in mucin synthesis and the activation of the exocytic pathway, which results in mucus hypersecretion. The process of mucin secretion involves multiple steps and relies on the recruitment of particular proteins, such as members of the exocyst family and ezrin $(4,5)$, that facilitate the activation and exocytosis of mucin granules. In airway goblet cells, the exocytic complex functions as essential fusion machinery for vesicle trafficking during MUC5AC secretion; however, the molecular composition of this complex and the mechanism of membrane fusion during MUC5AC granule exocytosis are not fully established at present. 


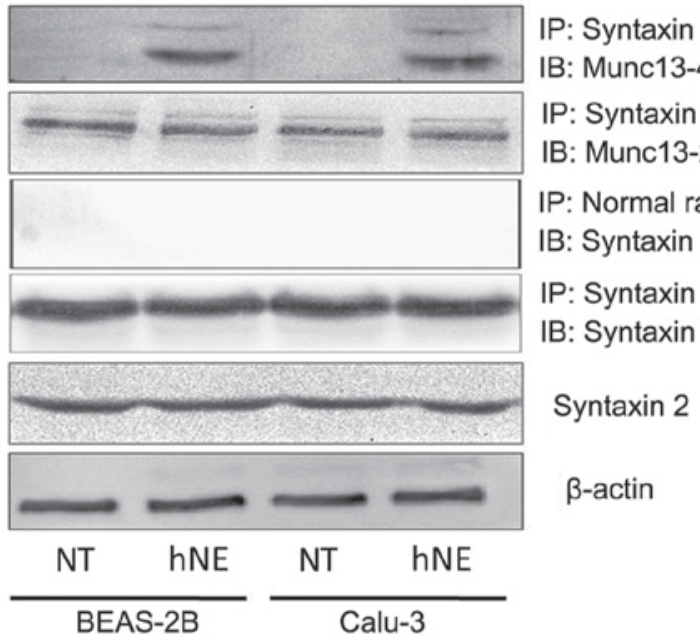

Figure 4. CoIP analysis of Munc13-2 and Munc13-4 binding to syntaxin2 in BEAS-2B cells and Calu-3 cells. Supernatants of cell lysates containing total cellular protein were standardized to equal protein concentrations using Bicinchoninic Acid Protein assays. Prior to CoIP analysis, the standardized proteins were loaded onto an SDS-PAGE gel. Normal rabbit IgG was used as a negative control for CoIP. Following CoIP, the captured antigen-antibody samples were prepared for western blotting to visualize Munc13-2 and Munc13-4 expression. CoIP, co-immunoprecipitation; Munc13-2, unc-13 homolog B; Munc13-4, unc-13 homolog D; IP, immunoprecipitation; IB, antibody; hNE, human neutrophil elastase; NT, no hNE treatment.

The final steps of vesicular trafficking mediate the docking and fusion of SGs with the plasma membrane. Previous studies have identified the components of the exocytic machinery involved in this process and have delineated their essential functions in protists and mammalian nerve cells; however, the tethering, docking and membrane fusion processes employed during mucin granule exocytosis in the airway require further investigation. The central components of this process are soluble SNARE proteins present on secretory vesicles (v-SNAREs) and their target membrane proteins (t-SNAREs) $(24,25)$. In MUC5AC SG exocytosis, the combination of VAMP8 and SNAP23 has been demonstrated to be essential in the docking and fusion of SGs and plasma membranes (26). As one of the most important SG activators, the Munc13 family was originally investigated in Caenorhabditis elegans. Further studies in mammalian secretory cells revealed that the Munc13 family not only acts as the crucial activator of SGs in the nervous system, but is also indispensable for the activation of SGs in non-nervous system secretory cells $(27,28)$. The specific mechanisms involved in the promotion of SG activation by Munc13 have not been fully elucidated. Studies in neuronal cells have indicated that Munc13 may promote the depolymerization of syntaxin-Munc18 complexes and maintain the stability of syntaxin, which may promote the combination of VAMP and SNAP25 $(23,29-32)$. Previously, syntaxin2 was demonstrated to be localized in human airway goblet cells and was implicated in regulating mucin SG exocytosis (33).

In the present study, the functions of the Munc13 family in the BEAS-2B and Calu-3 immortalized human airway epithelial cell lines were investigated, which are the most commonly used cell lines for studies on airway mucin SG exocytosis due to the similarity of their physical characteristics
A
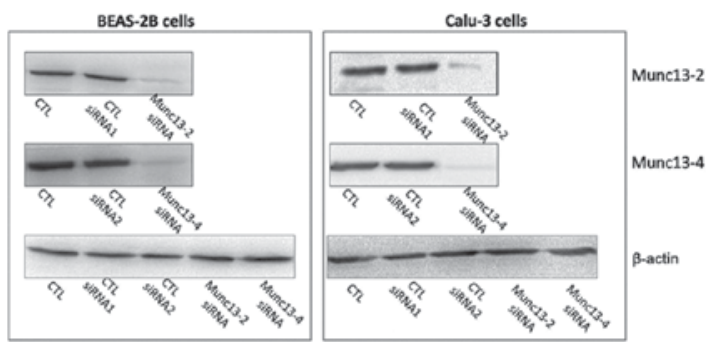

B

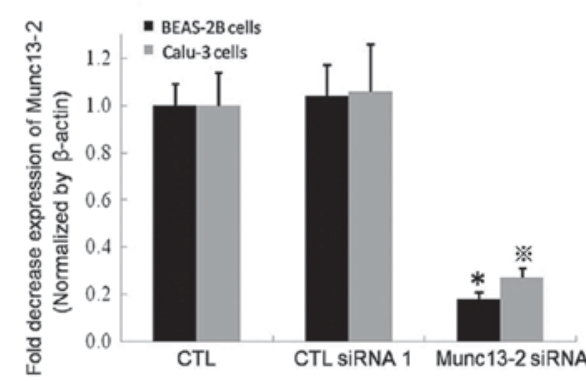

C

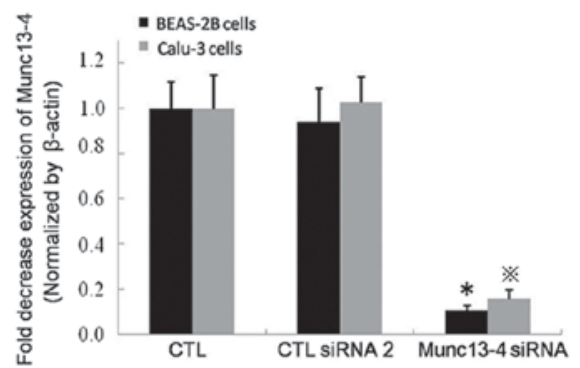

Figure 5. siRNA-mediated inhibition of Munc13-2 and Munc13-4 synthesis Untransfected cells (CTL) were employed as controls. Cells were transfected with Munc13-2 siRNA, Munc13-4 siRNA or CTL siRNA. CTL siRNA1 exhibited a similar GC content to the Munc13-2-specific siRNA, while CTL siRNA2 exhibited a similar GC content to the Munc13-4-specific siRNA. (A) Protein expression levels of Munc13-2 andMunc13-4 in the transfected cells were analyzed by western blotting. Representative bands are presented for each protein. Protein levels of (B) Munc13-2 and (C) Munc13-4 quantified by densitometric analysis are presented as fold changes compared with untransfected cells. ${ }^{*} \mathrm{P}<0.05$ vs. CTL or CTL siRNA1/2 BEAS-2B cells; ${ }^{*} \mathrm{P}<0.05$ vs. CTL or CTL siRNA1/2Calu-3 cells. siRNA, small interfering RNA; Munc13-2, unc-13 homolog B; Munc13-4, unc-13 homolog D; CTL siRNA, control siRNA; CTL group, untransfected cells.

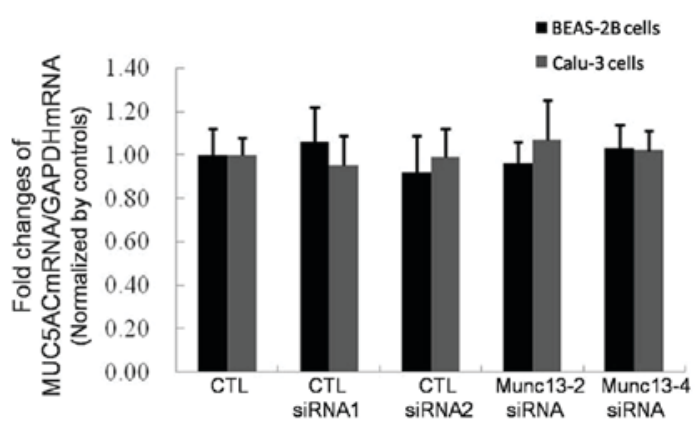

Figure 6. MUC5AC mRNA expression levels in Munc13-2- or Munc13-4-knockdown cells were analyzed by reverse transcription-quantitative polymerase chain reaction. Untransfected cells were employed as controls. Cells were transfected with Munc13-2 siRNA, Munc13-4 siRNA or CTLsiRNAs. CTLsiRNA1 exhibited a similar GC content to the Munc13-2-specific siRNA, while CTL siRNA2 exhibited a similar GC content to the Munc13-4-specific siRNA. MUC5AC, mucin 5AC; Munc13-2, unc-13 homolog B; Munc13-4, unc-13 homolog D; siRNA, small interfering RNA; CTL siRNA, control siRNA; CTL group, untransfected cells. 

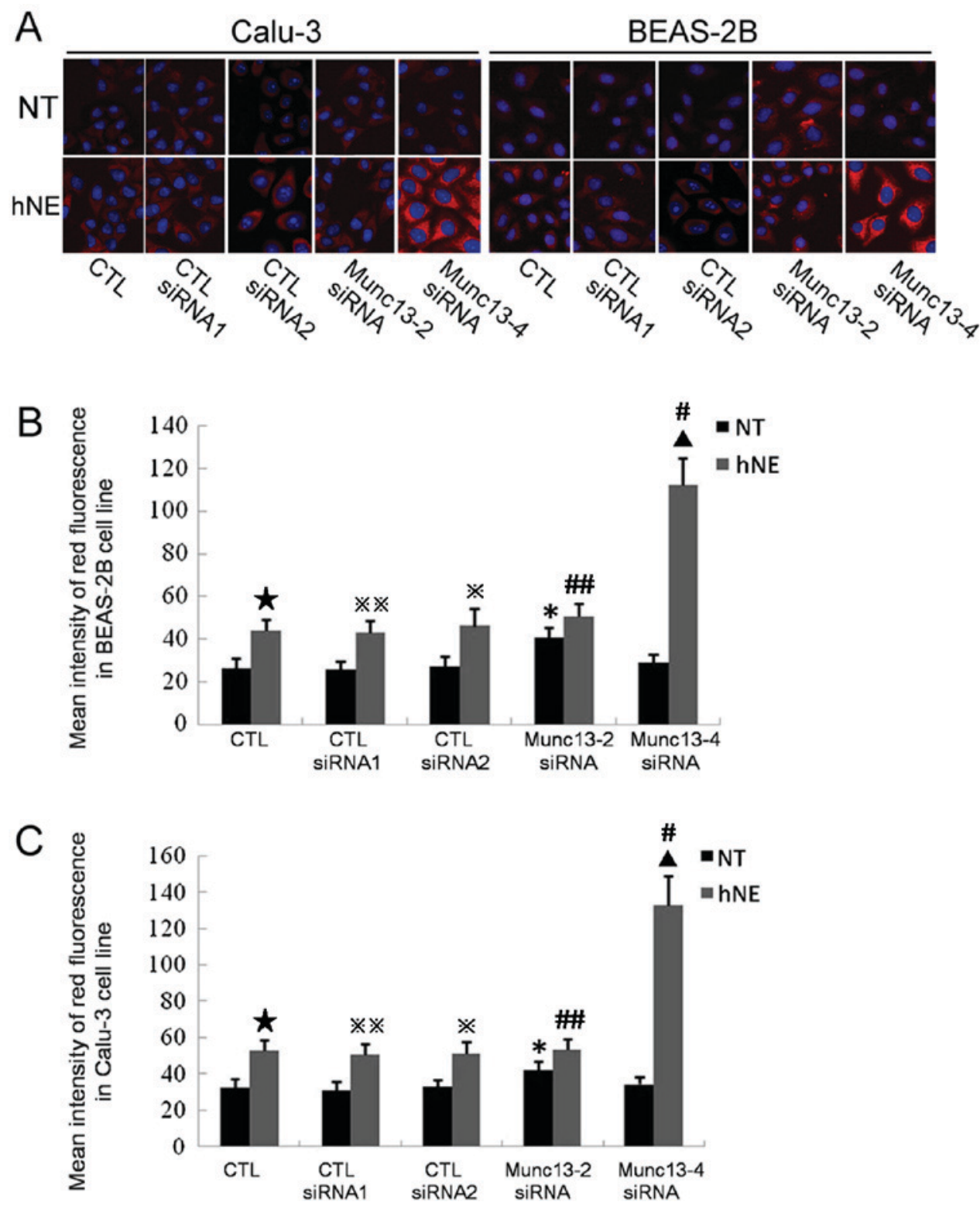

Figure 7. Effects of Munc13-2 or Munc13-4 knock down on the expression levels of retained intracellular MUC5AC. Untransfected cells were employed as controls. Cells were transfected with Munc13-2 siRNA, Munc13-4 siRNA or CTL siRNAs. CTL siRNA1 exhibited a similar GC content to the Munc13-2-specific siRNA, while CTL siRNA2 exhibited a similar GC content to the Munc13-4-specific siRNA. Intracellular MUC5AC protein (red fluorescence) was visualized with a tetramethylrhodamine-conjugated secondary antibody bound to a MUC5AC primary antibody. Nuclei were labeled with DAPI (blue fluorescence). hNE-treated cells were exposed to a $100 \mathrm{nM} \mathrm{hNE}$ solution for $1 \mathrm{~h}$. (A) Images were captured using a laser confocal microscope at an original magnification of $\mathrm{x} 400 \mathrm{in}$ six independent experiments. Quantification and statistical analysis of intracellular MUC5AC in (B) BEAS-2B cells and (C) Calu-3 cells. The red fluorescence intensity of 20 cells on each slide was measured. The results were recorded and calculated using Leica Microsystem software. "P<0.05 vs. CTL, CTL siRNA1-transfected cells or CTL siRNA2-transfected cells with NT; ${ }^{\wedge} \mathrm{P}<0.05$ vs. CTL, CTL siRNA1-transfected cells or CTL siRNA2-transfected cells with hNE treatment. ${ }^{\star} \mathrm{P}<0.05$ vs. CTL with $\mathrm{NT},{ }^{*} \mathrm{P}<0.05$ vs. CTLsiRNA2-transfected cells with $\mathrm{NT}$, ${ }^{*}{ }^{*} \mathrm{P}<0.05$ vs. CTL siRNA1-transfected cells with NT, ${ }^{~} \mathrm{P}<0.05$ vs. Munc13-4-transfected cells with NT, ${ }^{\# / P} \mathrm{P}<0.05$ vs. Munc13-2-transfected cells with NT. Munc13-2, unc-13 homolog B; Munc13-4, unc-13 homolog D; MUC5AC, mucin 5AC; siRNA, small interfering RNA; CTL siRNA, control siRNA; hNE, human neutrophil elastase; CTL group, untransfected cells; NT, no hNE treatment.

to those of human airway goblet cells $(33,34)$. To date, two isoforms of the Munc13 family, Munc13-2 and Munc13-4, have been isolated from the human airway epithelium (35). According to the in vitro assay results of the present study, hNE may not influence the synthesis of Munc13-2 or Munc13-4; however, hNE stimulation recruited Munc13-4, but not Munc13-2, to the cellular plasma membrane. The binding of Munc13-2 and Munc13-4 to syntaxin 2 was also investigated in the present study, which is the major syntaxin subtype involved in airway mucin SG exocytosis. The present study reported that Munc13-2 exhibits a stable bond with syntaxin 2 in response to with or without hNE stimulation; syntaxin2-Munc13-4 complexes were rare in both cell lines, but they increased in number following stimulation with hNE. These results indicate that Munc13-4 may be sensitive to hNE stimulation during airway mucin hypersecretion. To further investigate this hypothesis, siRNA was employed to individually downregulate Munc13-2 and Munc13-4 within the two cell lines and analyze the subsequent secretion of MUC5AC in the present study. No significant differences in 

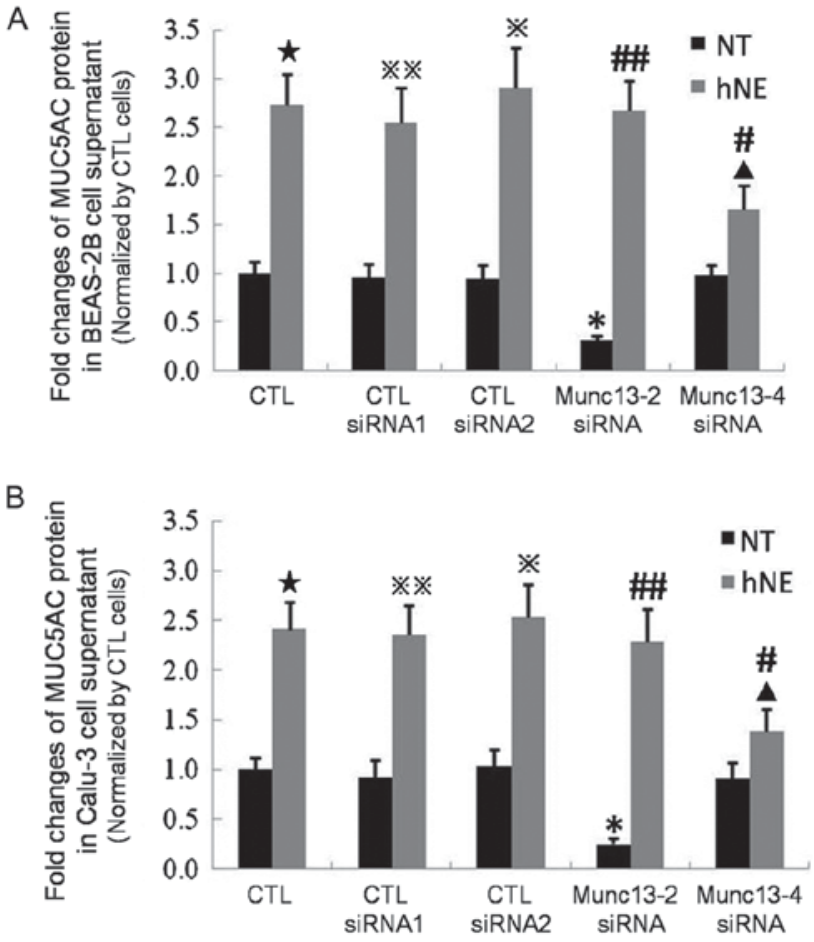

Figure 8. Secreted MUC5AC protein expression levels in the cell culture supernatants of Munc13-2- and Munc13-4-knockdown BEAS-2B and Calu-3 cells were measured by ELISA. Untransfected cells were employed as controls. Cells were transfected with Munc13-2 siRNA, Munc13-4 SiRNA or CTL siRNA. CTL siRNA1 exhibited a similar GC content to the Munc13-2-specific siRNA, while CTL siRNA2 exhibited a similar GC content to the Munc13-4-specific siRNA. ELISA was performed to determine MUC5AC protein levels in the cell culture supernatants of (A) BEAS-2B and (B) Calu-3 cell lines. The results were recorded as fold changes compared with the CTL group. "P $<0.05$ vs. CTL, CTL siRNA1 and CTL siRNA2 NT groups; ${ }^{\wedge} \mathrm{P}<0.05$ vs. CTL, CTL siRNA1 and CTL siRNA2 hNE groups. ${ }^{\star} \mathrm{P}<0.05$ vs. CTL with NT, ${ }^{*} \mathrm{P}<0.05$ vs. CTL siRNA2-transfected cells with NT, ${ }^{*} * \mathrm{P}<0.05$ vs. CTL siRNA1-transfected cells with NT, ${ }^{*} \mathrm{P}<0.05$ vs. Munc13-4-transfected cells with NT, ${ }^{\# \#} \mathrm{P}<0.05$ vs. Munc13-2-transfected cells with NT. MUC5AC, mucin 5AC; Munc13-2, unc-13 homolog B; Munc13-4, unc-13 homolog D; siRNA, small interfering RNA; CTL siRNA, control siRNA; CTL group, untransfected cells; hNE, human neutrophil elastase; NT, no hNE treatment.

MUC5AC mRNA expression were detected in untransfected, Munc 13-2-knockdown or Munc13-4-knockdown cells for either the BEAS-2B or Calu-3 cell lines. Munc13-2-knockdown cells partially lost their baseline MUC5AC exocytosis ability, where as Munc13-4-defective cells retained this ability. These data indicate that Munc13-2, but not Munc13-4, may be an essential regulator of baseline MUC5AC exocytosis, which is consistent with previous investigation within a mouse model (13). hNE was employed in the present study to induce MUC5AC hypersecretion in both cell lines. Unlike Munc13-4-knockdown cells, Munc13-2-knockdown cells retained the majority of their sensitivity to hNE when in MUC5AC hypersecretion mode, indicating that Munc13-4 may be an essential regulator of MUC5AC SG hypersecretion, at least in the presence of hNE. Conversely, Munc13-2 appears to participate in baseline MUC5AC exocytosis rather than agonist-induced MUC5AC hypersecretion. The present study indicated the crucial role of Munc13-2 in the basal MUC5AC exocytosis and the essential role of Munc13-4 in hNE-induced MUC5AC hypersecretion mode. Beyond core complex composed by v-SNARE and t-SNARE, the tethering docking and releasing of secretory granules (SGs) depend on a series of multi-subunit protein complexes, including EEA1, the Rab family and its effector (36). The complex interrelationships between these proteins and the core complex are understood in yeast and neuronal SGs. However, they are still ambiguous in nonneuronal SGs. As a majority of the functional relationships between the SNARE complex members in the exocytosis of airway MUC5AC SGs are still unknown, further researches on the functional bindings of SNARE complex members in the tethering docking and releasing of MUC5AC SGs will be performed in the future. In conclusion, Munc13 family members act as important activators of MUC5AC granule secretion. Munc13-2 may be an essential regulator of baseline MUC5AC exocytosis, whereas Munc13-4 appears to be sensitive to hNE stimulation during airway MUC5AC hypersecretion. The present study has extended our current knowledge about the tethering/docking procedure during MUC5AC hyper-secretion and provides potential targets for the development of novel therapy in the management of postinfectious airway mucus hypersecretion.

\section{Acknowledgements}

Not applicable.

\section{Funding}

The present study was supported by grants from the National Nature Science Foundation of China (grant nos. 81660010, 81500015 and 81611530713) and Russian Foundation for Basic Research (RFBR, grant no. 17-54-53162).

\section{Availability of data and materials}

All data generated or analyzed during this study are included in this published article.

\section{Authors' contributions}

XZ designed the research and participated in its coordination. RX carried out the CoIP and western blotting experiments and participated in drafting the manuscript. QL performed the RT-qPCR and confocal microscopy analyses. JMP and VPK prepared the siRNA and cell transfection. JZ performed the statistical analysis. All authors were involved in the data interpretation and writing of the paper. All authors read and approved the final manuscript.

\section{Ethics approval and consent to participate}

Not applicable.

\section{Consent for publication}

Not applicable.

\section{Competing interests}

The authors declare that they have no competing interests. 


\section{References}

1. Thai P, Loukoianov A, Wachi S and Wu R: Regulation of airway mucin gene expression. Annu Rev Physiol 70: 405-429, 2008.

2. Turner $\mathbf{J}$ and Jones CE: Regulation of mucin expression in respiratory diseases. Biochem Soc Trans 37: 877-881, 2009.

3. Voynow JA and Rubin BK: Mucins, mucus, and sputum. Chest 135: 505-512, 2009.

4. Kimura RE: Fatty acid metabolism in the fetus. Semin Perinatol 13: 202-210, 1989.

5. Li Q, Li N, Liu CY, Xu R, Kolosov VP, Perelman JM and Zhou XD: Ezrin/Exocyst complex regulates mucin 5AC secretion induced by neutrophil elastase in human airway epithelial cells. Cell Physiol Biochem 35: 326-338, 2015.

6. Adler KB, Tuvim MJ and Dickey BF: Regulated mucin secretion from airway epithelial cells. Front Endocrinol (Lausanne) 4: 129 , 2013.

7. Jones LC, Moussa L, Fulcher ML, Zhu Y, Hudson EJ, O'Neal WK, Randell SH, Lazarowski ER, Boucher RC and Kreda SM: VAMP8 is a vesicle SNARE that regulates mucin secretion in airway goblet cells. J Physiol 590: 545-562, 2012.

8. Tuvim MJ, Mospan AR, Burns KA, Chua M, Mohler PJ Melicoff E, Adachi R, Ammar-Aouchiche Z, Davis CW and Dickey BF: Synaptotagmin 2 couples mucin granule exocytosis to $\mathrm{Ca} 2+$ signaling from endoplasmic reticulum. J Biol Chem 284: 9781-9787, 2009.

9. Feldmann J, Callebaut I, Raposo G, Certain S, Bacq D, Dumont C, Lambert N, Ouachée-Chardin M, Chedeville G, Tamary H, et al: Munc13-4 is essential for cytolytic granules fusion and is mutated in a form of familial hemophagocytic lymphohistiocytosis (FHL3). Cell 115: 461-473, 2003.

10. Kabachinski G, Yamaga M, Kielar-Grevstad DM, Bruinsma S and Martin TF: CAPS and Munc13 utilize distinct PIP2-linked mechanisms to promote vesicle exocytosis. Mol Biol Cell 25 508-521, 2014.

11. Rhee JS, Betz A, Pyott S, Reim K, Varoqueaux F, Augustin I, Hesse D, Südhof TC, Takahashi M, Rosenmund C and Brose N: Beta phorbol ester- and diacylglycerol-induced augmentation of transmitter release is mediated by Munc13s and not by PKCs. Cell 108: 121-133, 2002.

12. Andrews-Zwilling YS, Kawabe H, Reim K, Varoqueaux F and Brose N: Binding to Rab3A-interacting molecule RIM regulates the presynaptic recruitment of Munc13-1 and ubMunc13-2. J Biol Chem 281: 19720-19731, 2006.

13. Zhu Y, Ehre C, Abdullah LH, Sheehan JK, Roy M, Evans CM, Dickey BF and Davis CW: Munc13-2-/- baseline secretion defect reveals source of oligomeric mucins in mouse airways. J Physiol 586: 1977-1992, 2008.

14. Boswell KL, James DJ, Esquibel JM, Bruinsma S, Shirakawa R, Horiuchi $\mathrm{H}$ and Martin TF: Munc13-4 reconstitutes calcium-dependent SNARE-mediated membrane fusion. J Cell Biol 197: 301-312, 2012.

15. Elstak ED, te Loo M, Tesselaar K, van Kerkhof P, Loeffen J, Grivas D, Hennekam E, Boelens JJ, Hoogerbrugge PM, van der Sluijs P, et al: A novel Dutch mutation in UNC13D reveals an essential role of the C2B domain in munc13-4 function. Pediatr Blood Cancer 58: 598-605, 2012.

16. Livak KJ and Schmittgen TD: Analysis of relative gene expression data using real-time quantitative PCR and the 2(-Delta Delta C(T)) method. Methods 25: 402-408, 2001.

17. Li M, Li Q, Yang G, Kolosov VP, Perelman JM and Zhou XD: Cold temperature induces mucin hypersecretion from normal human bronchial epithelial cells in vitro through a transient receptor potential melastatin 8 (TRPM8)-mediated mechanism. J Allergy Clin Immunol 128: 626-634.e1-e5, 2011.
18. Guan R, Dai H and Rizo J: Binding of the Munc13-1 MUN domain to membrane-anchored SNARE complexes. Biochemistry 47: 1474-1481, 2008.

19. Daily NJ, Boswell KL, James DJ and Martin TF: Novel interactions of CAPS (Ca2+-dependent activator protein for secretion) with the three neuronal SNARE proteins required for vesicle fusion. J Biol Chem 285: 35320-35329, 2010.

20. Kreda SM, Okada SF, van Heusden CA, O'Neal W, Gabriel S, Abdullah L, Davis CW, Boucher RC and Lazarowski ER: Coordinated release of nucleotides and mucin from human airway epithelial Calu-3 cells. J Physiol 584: 245-259, 2007.

21. Shukla A, Berglund L, Nielsen LP, Nielsen S, Hoffmann HJ and Dahl R: Regulated exocytosis in immune function: Are SNARE-proteins involved? Respir Med 95: 773-780, 2001.

22. ter Beest MB, Chapin SJ, Avrahami D and Mostov KE: The role of syntaxins in the specificity of vesicle targeting in polarized epithelial cells. Mol Biol Cell 16: 5784-5792, 2005.

23. Sassa T, Harada S, Ogawa H, Rand JB, Maruyama IN and Hosono R: Regulation of the UNC-18-Caenorhabditis elegans syntaxin complex by UNC-13. J Neurosci 19: 4772-4777, 1999.

24. Davis CW and Dickey BF: Regulated airway goblet cell mucin secretion. Annu Rev Physiol 70: 487-512, 2008.

25. Brunger AT: Structure and function of SNARE and SNARE-interacting proteins. Q Rev Biophys 38: 1-47, 2005.

26. Stackl W, Hasun $R$ and Marberger M: Intracavernous injection of prostaglandin E1 in impotent men. J Urol 140: 66-68, 1988.

27. Elstak ED, Neeft M, Nehme NT, Voortman J, Cheung M, Goodarzifard M, Gerritsen HC, van Bergen En Henegouwen PM, Callebaut I, de Saint Basile G and van der Sluijs P: The munc13-4-rab27 complex is specifically required for tethering secretory lysosomes at the plasma membrane. Blood 118: 1570-1578, 2011

28. Caviglia S, Brankatschk M, Fischer EJ, Eaton S and Luschnig S: Staccato/Unc-13-4 controls secretory lysosome-mediated lumen fusion during epithelial tube anastomosis. Nat Cell Biol 18: 727-739, 2016.

29. Betz A, Ashery U, Rickmann M, Augustin I, Neher E, Südhof TC, Rettig $\mathbf{J}$ and Brose N: Munc13-1 is a presynaptic phorbol ester receptor that enhances neurotransmitter release. Neuron 21: 123-136, 1998

30. Rizo J and Südhof TC: Snares and Munc18 in synaptic vesicle fusion. Nat Rev Neurosci 3: 641-653, 2002.

31. Zhu D, Xie L, Kang Y, Dolai S, Bondo Hansen J, Qin T, Xie H, Liang T, Rubin DC, Osborne L and Gaisano HY: Syntaxin 2 acts as inhibitory SNARE for insulin granule exocy tosis. Diabetes 66: 948-959, 2017.

32. Christie MP, Hu SH, Whitten AE, Rehman A, Jarrott RJ, King GJ, Collins BM and, Martin JL: Revisiting interaction specificity reveals neuronal and adipocyte Munc18 membrane fusion regulatory proteins differ in their binding interactions with partner SNARE Syntaxins. PLoS One 12: e0187302, 2017.

33. Ou SK, McDonald C and Patterson PH: Comparison of two techniques for targeting the production of monoclonal antibodies against particular antigens. J Immunol Methods 145: 111-118, 1991.

34. Zhou J, Perelman JM, Kolosov VP and Zhou X: Neutrophil elastase induces MUC5AC secretion via protease-activated receptor 2. Mol Cell Biochem 377: 75-85, 2013.

35. Koch H, Hofmann $\mathrm{K}$ and Brose N: Definition of Munc13-homology-domains and characterization of a novel ubiquitously expressed Munc13 isoform. Biochem J 349: 247-253, 2000.

36. Grosshans BL, Ortiz D and Novick P: Rabs and their effectors: Achieving specificity in membrane traffic. Proc Natl Acad Sci USA 103: 11821-11827, 2006. 